\title{
CORRIGENDUM
}

\section{Warranted religion: answering objections to Alvin Plantinga's epistemology - CORRIGENDUM}

\author{
TYLER DALTON MCNABB
}

DOI: 10.1017/Soo3441251400033X, Published by Cambridge University Press, 18 September 2014.

The references in the listed endnotes should read as follows:

23. Armstrong (1995), 35, 47.

32. Plantinga \& Tooley (2008), 26.

45. Harrison (2012), 58.

47. Shankara, Isherwood, \& Vivekananda (1978), 104.

\section{Reference}

McNabb, Tyler Dalton (2014) Warranted religion: answering objections to Alvin Plantinga's epistemology, Religious Studies (Cambridge: Cambridge University Press), first published online 18 September 2014, DOI: $10.1017 /$ So03441251400033X. 